\title{
Reorganization of polymer structures based on dynamic covalent chemistry: polymer reactions by dynamic covalent exchanges of alkoxyamine units
}

\author{
Hideyuki Otsuka ${ }^{1,2}$
}

The recent progress of research on polymer reactions utilizing dynamic covalent exchanges of alkoxyamine units-adducts of styryl and stable nitroxide radicals-is reviewed. The alkoxyamine derivatives derived from 2,2,6,6-tetramethylpiperidine-1-oxy (TEMPO, a stable free radical) are frequently utilized as unimolecular initiators for the nitroxide-mediated radical polymerizations. In the absence of monomers, however, the alkoxyamine derivatives can undergo intermolecular crossover reactions via a radical process upon heating. The central $\mathrm{C}-\mathrm{ON}$ bonds in the alkoxyamine derivatives reversibly cleave and reform upon heating, and a mixture of alkoxyamine derivatives is able to equilibrate thermally, meaning that the covalent bonds in the alkoxyamine derivatives are considered as 'dynamic covalent bonds.' Unlike conventional polymers, the structures and constitutions of polymers with dynamic covalent bonds, dynamic covalent polymers, can be reorganized under appropriate conditions even after polymerization. In the present review, various types of macromolecular design, polymer reactions based on dynamic covalent exchanges of alkoxyamine units and their related research are described. Various examples of polymer reactions of main-chain-type, side-chain-type, crosslinked and star-shaped poly(alkoxyamine)s are systematically shown. Furthermore, the progress of the polymer reactions can be confirmed by diverse characterization techniques, such as spectroscopic, chromatographic, microscopic and scattering methods.

Polymer Journal (2013) 45, 879-891; doi:10.1038/pj.2013.17; published online 6 March 2013

Keywords: alkoxyamines; dynamic covalent chemistry; dynamic covalent polymers; polymer architectures; polymer reactions; stimulus-responsive polymers

\section{INTRODUCTION}

Reorganizable polymers have attracted considerable attention in recent decades because their primary structures and properties can be changed and manipulated even after polymerization. However, most conventional polymers are structurally unchangeable because their molecular structures are composed of strong and fixed covalent bonds. Therefore, reorganizable polymers should consist of monomer units reversibly connected by exchangeable covalent and/or noncovalent bonds, and they have the potential to be applied to the design of intelligent materials, chemical recycling systems, polymer hybridization and so on. 'Supramolecular polymers' are representative successful examples of reorganizable polymers, and are constructed by secondary non-covalent interactions such as hydrogen bonding. The pioneering example of a supramolecular polymer was first reported by Fréchet and Kato in $1989 .{ }^{1}$ Lehn et al. ${ }^{2}$ synthesized the first mainchain-type supramolecular polymer based on hydrogen bonding; since then, many examples of supramolecular polymers have been reported. ${ }^{3-6}$ For instance, Meijer et al. ${ }^{7}$ developed supramolecular main-chain polymers with very high molecular weights by using a quadruple hydrogen-bonding system. Unlike conventional polymers, supramolecular polymers connected by hydrogen bonds are not very stable, but rather, are mutable, particularly in the solution state. Their superstructures and their molecular weights are strongly dependent on concentration and solvent quality. Therefore, it is relatively difficult to characterize their detailed structures further.

On the other hand, successful applications of reversible covalent chemistry have been seen in the development of dynamic combinatorial libraries, ${ }^{8-14}$ interlocked molecules, ${ }^{15-21}$ drug discovery ${ }^{22}$ and controlled release of fragrances. ${ }^{23}$ Rowan et al. ${ }^{24}$ introduced the concept of dynamic covalent chemistry, which offered the possibility of 'doing supramolecular chemistry' at the level of covalent bonds. When the main chain of a polymer consists of reversible covalent bonds instead of non-covalent interactions, the polymer is expected to behave as a reorganizable polymer, similarly to supramolecular polymers (Figure 1). ${ }^{25,26}$ In contrast to supramolecular polymers, one can manipulate the stability and reorganizability of 'dynamic covalent polymers 27 by selecting the proper reversible covalent bonds. If a thermally reversible covalent system is employed, the polymers are

${ }^{1}$ Institute for Materials Chemistry and Engineering, Kyushu University, Fukuoka, Japan and ${ }^{2}$ International Research Center for Molecular Systems, Kyushu University, Fukuoka, Japan

Correspondence: Professor H Otsuka, Institute for Materials Chemistry and Engineering, Kyushu University, Nishi-ku, Fukuoka 819 0395, Japan.

E-mail: otsuka@ms.ifoc.kyushu-u.ac.jp

Received 30 November 2012; revised 30 December 2012; accepted 21 January 2013; published online 6 March 2013 


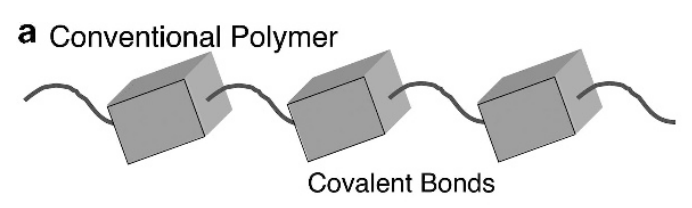

b Supramolecular Polymer

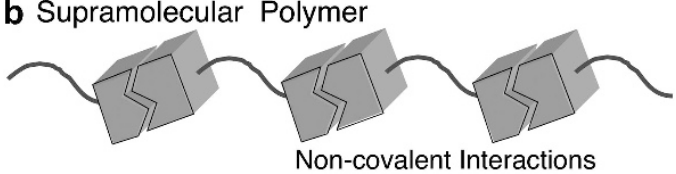

\section{Dynamic Covalent Polymer}

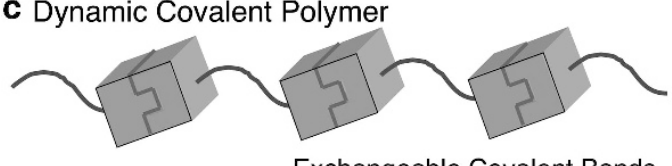

Figure 1 Schematic representation of (a) conventional polymers, (b) supramolecular polymers and (c) dynamic covalent polymers.

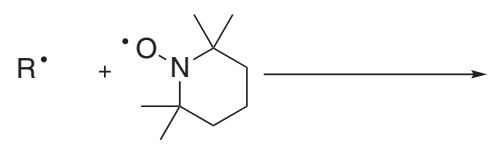

TEMPO

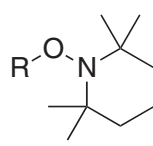

Alkoxyamine
Scheme 1 Formation of alkoxyamine from TEMPO.

stable under normal conditions and even at high dilution. Nevertheless, once they are exposed to an external stimulus (heating), they start to reorganize to reflect the chemical and physical environmental conditions.

Although some reversible covalent bonds have been used for structural change in the field of polymer chemistry, ${ }^{28-45}$ this review focuses on polymer reactions by dynamic covalent exchanges of alkoxyamine units derived from 2,2,6,6-tetramethylpiperidine-1-oxy (TEMPO, a stable free radical) derivatives (Scheme 1). The fundamental radical exchange reaction of alkoxyamine derivatives is shown by a model reaction using low-molecular-weight alkoxyamine compounds. Then, various types of macromolecular design and polymer reactions based on dynamic covalent exchanges of alkoxyamine units and their related research are described. Main-chain-type, side-chaintype, crosslinked and star-shaped alkoxyamine-containing dynamic covalent polymers are systematically described by diverse characterization techniques, such as spectroscopic, chromatographic, microscopic and scattering methods.

\section{ALKOXYAMINES AS DYNAMIC COVALENT EXCHANGE UNITS}

Since the discovery of nitroxide-mediated radical polymerization $(\mathrm{NMP})^{46,47}$ using TEMPO, alkoxyamines have been well known as structures of the propagating chain ends in NMP. ${ }^{48-54}$ The key step in NMP is the reversible capping of the polymer chain end by a stable nitroxide free radical species. ${ }^{55}$ Another significant advance with NMP was the recognition of an alkoxyamine as a unimolecular initiating agent, providing both the reactive initiating radical and the stable mediating nitroxide radical. ${ }^{56}$ By using the NMP method, monomers such as styrene and acrylate derivatives can be polymerized from alkoxyamine initiators (Scheme 2). ${ }^{57}$ In the case of the radical polymerization of styrene with two different unimolecular alkoxyamine initiators, Hawker et al. ${ }^{58}$ reported that the radical crossover of the mediating nitroxide moieties occurred at
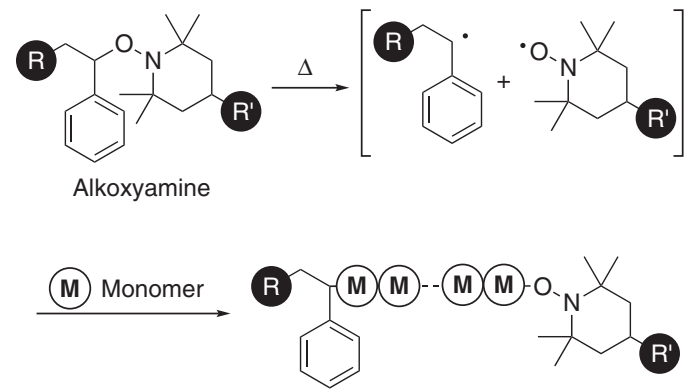

Radical Polymerization

Scheme 2 Nitroxide-mediated radical polymerization (NMP) from alkoxyamine.
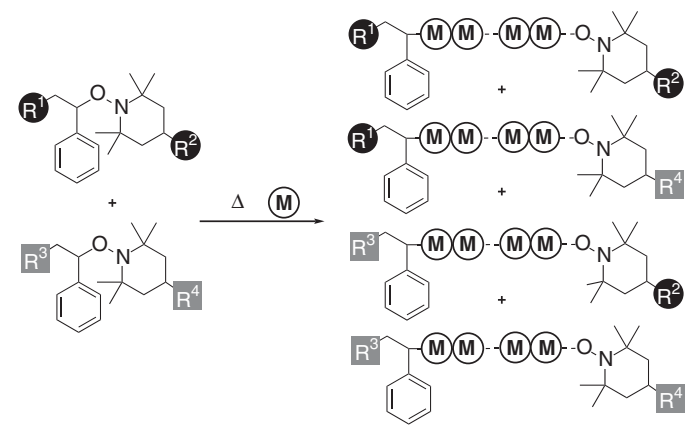

Scheme 3 Radical crossover of the mediating nitroxide moieties occurred at the termini of the growing polymer chains during NMP.

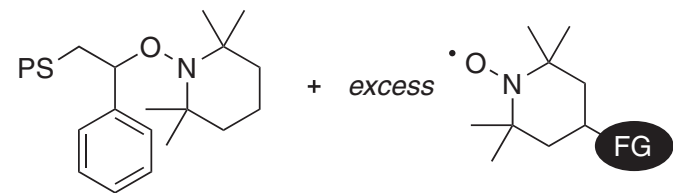

Alkoxyamine-terminated Polystyrene (PS)
TEMPO with Functional Group (FG)

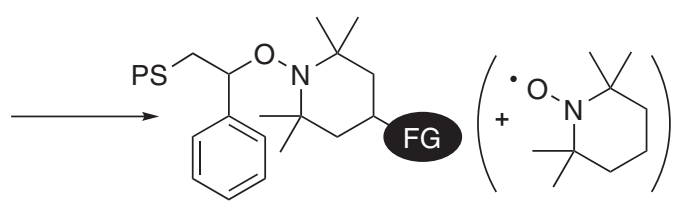

FG-terminated PS
Scheme 4 Exchange reaction with an excess amount of other nitroxide derivatives at the terminal group of the polystyrene prepared by NMP.

the termini of the growing polymer chains during polymerization, as shown in Scheme 3. Furthermore, an exchange reaction with an excess amount of other nitroxide derivatives at the terminal group of the polystyrene prepared by NMP was also reported by Turro et al. ${ }^{59}$ (Scheme 4). These results suggested that alkoxyamine derivatives have the potential to exchange with each other upon heating. Even though there was no monomer in the system, the alkoxyamine derivatives could be expected to scramble, as shown in Scheme 5, as a result of reversible $\mathrm{C}-\mathrm{ON}$ bond cleavage and formation upon heating, because the dissociation energy of the $\mathrm{C}-\mathrm{ON}$ bond in the alkoxyamine was reported to be $\sim 30 \mathrm{kcal} \mathrm{mol}^{-1}$.

To evaluate the exchangeability of alkoxyamine units, model exchange reactions using low-molecular-weight alkoxyamines were 


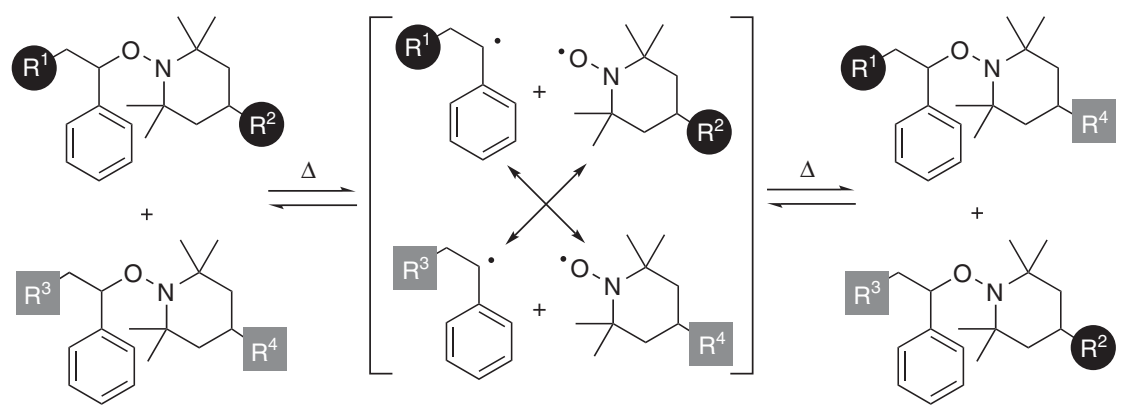

Scheme 5 Radical crossover of alkoxyamine derivatives in the absence of monomers.
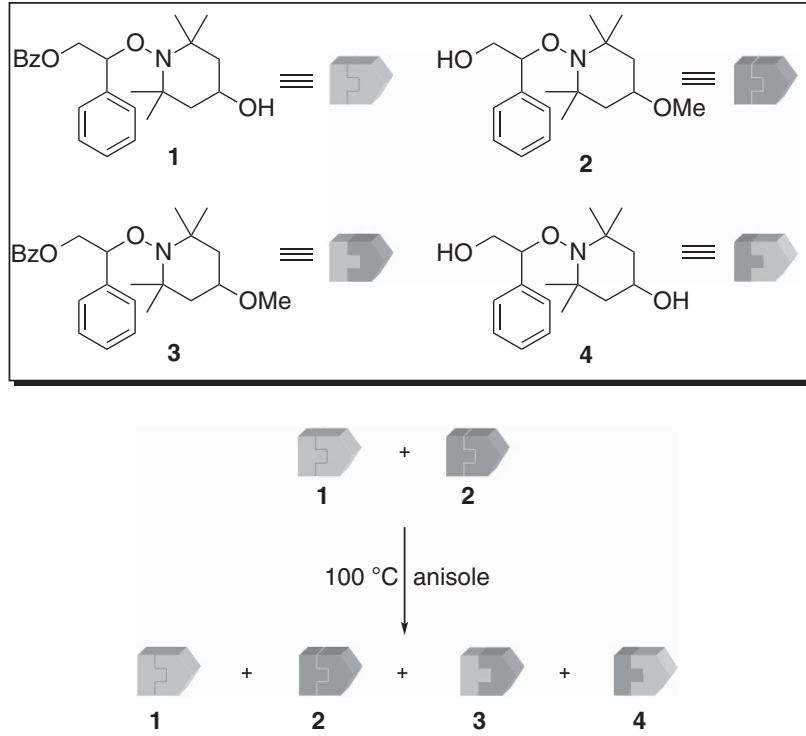

Scheme 6 Model reaction of radical crossoverusing alkoxyamine dervatives $1-4$ in anisole at $100{ }^{\circ} \mathrm{C}$.

performed. ${ }^{60}$ The reversible dissociation and formation of the C-ON bond in alkoxyamines were monitored as a crossover reaction between alkoxyamine derivatives. Alkoxyamine derivatives 1-4, bearing different substituents at both ends, were prepared, and model crossover reactions were carried out, as shown in Scheme 6. For example, equimolar amounts of $\mathbf{1}$ and $\mathbf{2}$ were mixed together in anisole as a $0.18 \mathrm{moll}^{-1}$ solution, and then heated at $100^{\circ} \mathrm{C}$. The reaction was followed by high performance liquid chromatography. From the results of these measurements, two additional peaks, assignable to 3 and $\mathbf{4}$, appeared soon after heating. Thin layer chromatographic analysis also supported the high performance liquid chromatography results. Significantly, the radical crossover reaction proceeded without any detectable side reaction such as carboncarbon coupling under these conditions. This observation is clearly explained by the persistent radical effect. ${ }^{47,61-64}$ Persistent radical effect is a general principle that explains the highly specific formation of the crosscoupling product $R^{1}-R^{2}$ between $R^{1}$ and $R^{2}$ when one species is persistent $\left(\mathrm{R}^{1}\right)$ and the other is transient. Persistent radical effect is observed when the persistent radical exists in excess over the transient radical. In the case of the crossover reaction of alkoxyamine derivatives, at the initial stage, a trace amount of coupling reaction inevitably occurs between the transient carbon radical species generated from the $\mathrm{C}-\mathrm{ON}$ bond and then generates a slight amount of TEMPO radical, which serves as the persistent radical. As the

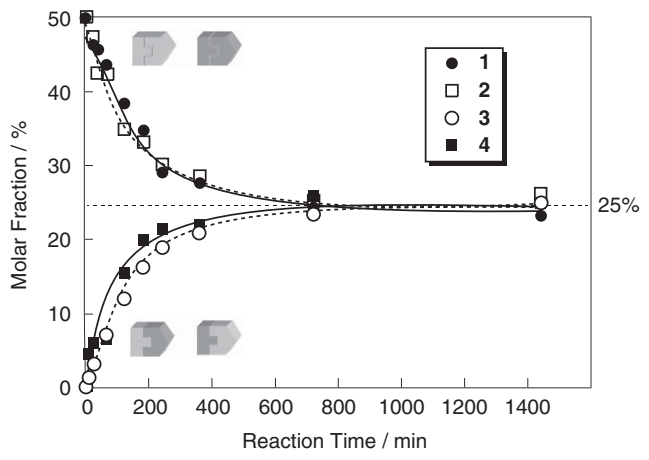

Figure 2 Molar fractions of alkoxyamine derivatives 1-4 after heating a mixture of $\mathbf{1}$ and $\mathbf{2}$ in anisole at $100^{\circ} \mathrm{C}$.

amount of the carbon-carbon coupling product is still small compared with that of alkoxyamines, the total crossover reactions seem to be highly specific.

The ratio of compounds $\mathbf{1 - 4}$ was estimated from the normalized peak areas in the high performance liquid chromatography analysis. As shown in Figure 2, the molar fractions of alkoxyamines 1-4 attained equilibrium after $12 \mathrm{~h}$ at $100{ }^{\circ} \mathrm{C}$. In this equilibrium state, the molar fractions were nearly identical, $25 \%$, for the four different alkoxyamine derivatives. Furthermore, the reaction rate strongly depended on the reaction temperature. The results revealed that the crossover reaction only occurred above $60^{\circ} \mathrm{C}$ and the molar fractions attained equilibrium earlier at higher reaction temperatures.

From these model experiments, it was inferred that alkoxyamines, via the exchange reaction, were promising candidates as the fundamental units in dynamic covalent polymers.

\section{REACTIONS OF MAIN-CHAIN-TYPE POLY(ALKOXYAMINE)S}

Main-chain-type alkoxyamine-containing dynamic covalent polymers were synthesized by step-growth polymerization (Scheme 7). Alkoxyamine-containing polyester (5) was prepared by polycondensation of diol 4 and adipoyl chloride in dichloromethane in the presence of pyridine at room temperature. ${ }^{60,65}$ Polyurethane $\mathbf{6}$, containing alkoxyamine units in the main chain, was prepared by the polyaddition of diol 4 with hexamethylene diisocyanate in the presence of dibutyltin dilaurate as a catalyst. ${ }^{66}$ The chemical structures of the obtained main-chain-type alkoxyamine-containing dynamic covalent polymers were fully characterized by ${ }^{1} \mathrm{H} \mathrm{NMR},{ }^{13} \mathrm{C}$ NMR and IR measurements. As alkoxyamine moieties are stable at room temperature, measurement of the polymer by gel permeation chromatography (GPC) successfully yielded the number-average molecular weight $\left(M_{\mathrm{n}}\right)$ and weight-average molecular weight $\left(M_{\mathrm{w}}\right)$. 


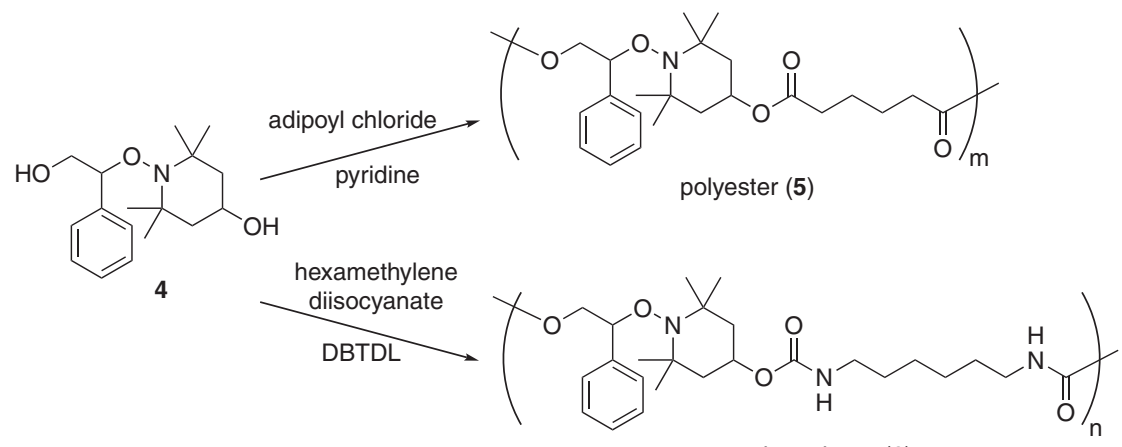

polyurethane (6)

Scheme 7 Preparation of main-chain-type alkoxyamine-containing dynamic covalent polymers, polyester $\mathbf{5}$ and polyurethane $\mathbf{6}$, by step-growth polymerization.
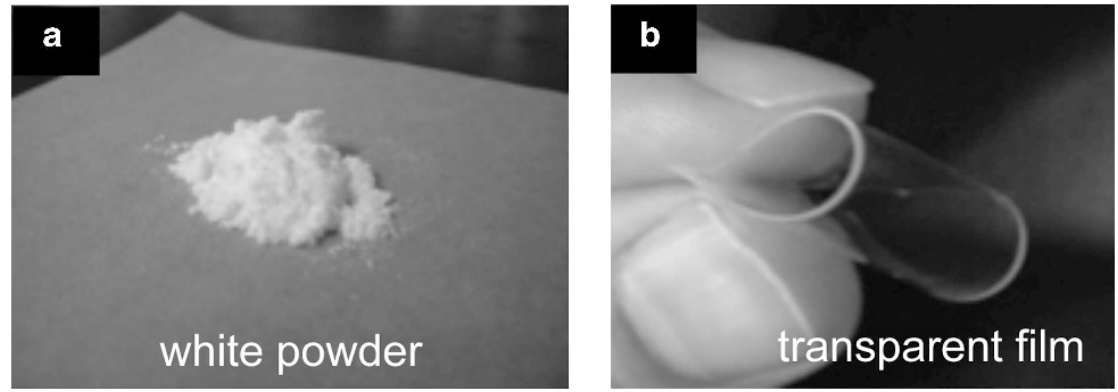

Figure 3 Photographs of alkoxyamine-containing polyurethane (6); (a) white powder obtained after reprecipitation and (b) transparent film prepared from a chloroform solution.

Under the experimental GPC conditions of $40^{\circ} \mathrm{C}$, no peak tailing and no drastic change of peak shape upon concentration change of the sample solutions were observed that would otherwise imply decomposition or reorganization of the polymer chains. Actually, the polymer was obtained as a white powder, and a transparent film could be prepared by slow evaporation of a chloroform solution, as shown in Figure 3. These results indicated that one can treat the alkoxyamine-containing dynamic covalent polymers at ambient temperature like conventional polymers due to their stability below $60^{\circ} \mathrm{C}$.

The thermal reaction behavior of the alkoxyamine-containing dynamic covalent polymers was completely different from conventional polymers. To investigate the thermal reactivity of the alkoxyamine-containing dynamic covalent polymers, polyester $\mathbf{5}$ was fractionated by preparative high performance liquid chromatography. The fractionated polyester $5 \mathrm{a}\left(M_{\mathrm{n}}=12000, M_{\mathrm{w}} / M_{\mathrm{n}}=1.21\right)$ was heated in anisole at $100{ }^{\circ} \mathrm{C}$ after degassing, and GPC and ${ }^{1} \mathrm{H}$ NMR measurements of the reacted polymers were carried out. Although the NMR spectrum did not change after heating for $24 \mathrm{~h}$, the GPC profiles drastically changed upon heating. The molecular weight distribution broadened with no significant change in the peak tops as the reaction proceeded. The phenomenon was undoubtedly attributed to the radical crossover reaction of the alkoxyamine units between the main chains. Figure 4 shows the $M_{\mathrm{n}}$ vs reaction time and the $M_{\mathrm{w}} / M_{\mathrm{n}}$ vs time plots for the thermal reaction behavior of polyester 5a in anisole at $100^{\circ} \mathrm{C}$. Although a slight change was observed for $M_{\mathrm{n}}, M_{\mathrm{w}} / M_{\mathrm{n}}$ drastically increased to $\sim 2.0$, which is the theoretical value for step-growth polymerization. No further changes in $M_{\mathrm{n}}$ and $M_{\mathrm{w}} / M_{\mathrm{n}}$ were observed after 6-12 h, indicating attainment of an equilibrium state. ${ }^{65}$ Furthermore, heating a mixture of a high-

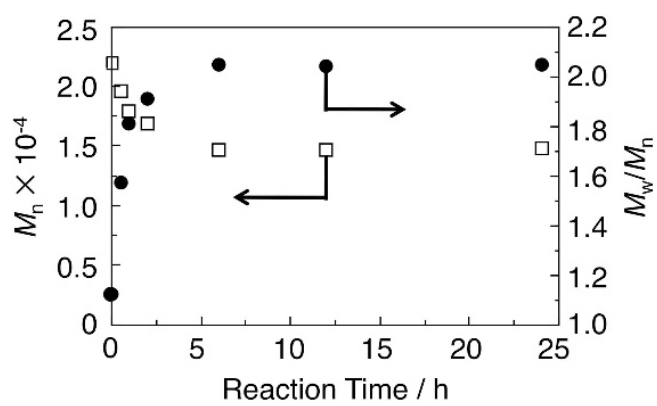

Figure 4 Changes in $M_{\mathrm{n}}$ and $M_{\mathrm{w}} / M_{\mathrm{n}}$ of alkoxyamine-containing polyester (5a), $\left(M_{\mathrm{n}}=12000, M_{\mathrm{w}} / M_{\mathrm{n}}=1.21\right)$ heated in anisole at $100^{\circ} \mathrm{C}$.

molecular-weight polymer and a low-molecular-weight polymer in anisole at $100^{\circ} \mathrm{C}$ for $24 \mathrm{~h}$ successfully resulted in the formation of the middle- molecular-weight polymer.

The concentration effect on the reorganization behavior of alkoxyamine-containing dynamic covalent polymers was investigated by using macrocyclic alkoxyamines. A macrocycle with alkoxyamine units was synthesized and its dynamic polymerization behavior was evaluated. ${ }^{67,68}$ For example, a macrocyclic alkoxyamine, the $[2+2]$ adduct (7), was synthesized by condensation of an alkoxyamine-based diol (4) with adipoyl chloride under high-dilution conditions. Macrocycle 7 acted as a monomer for 'ring-crossover' polymerization to afford the corresponding cyclic oligomer or polymer (8) with $M_{\mathrm{n}}=2000-18000$ due to the intermolecular radical crossover reaction. The structure of polymer $\mathbf{8}$ was identical to that of polymer 5 except that it was linear rather than cyclic. 
<smiles>CC1(C)CC(O)CC(C)(C)N1OC(CO)c1ccccc1</smiles>

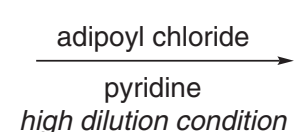<smiles>CC(C)(C)C(COC(=O)CCCCC(=O)OC1CC(C)(C)N(OC(COC(=O)CCCCC(=O)O)c2ccccc2)C(C)(C)C1)ON1C(C)(C)CC(OC(=O)CCCCC(=O)OCC(c2ccccc2)c2ccccc2)CC1(C)C</smiles>

[2+2] macrocycle (7)

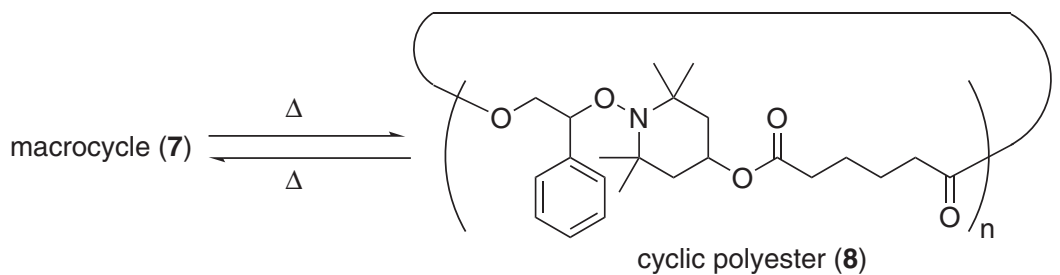

Scheme 8 Preparation and ring-crossover polymerization of macrocyclic alkoxyamine 7.

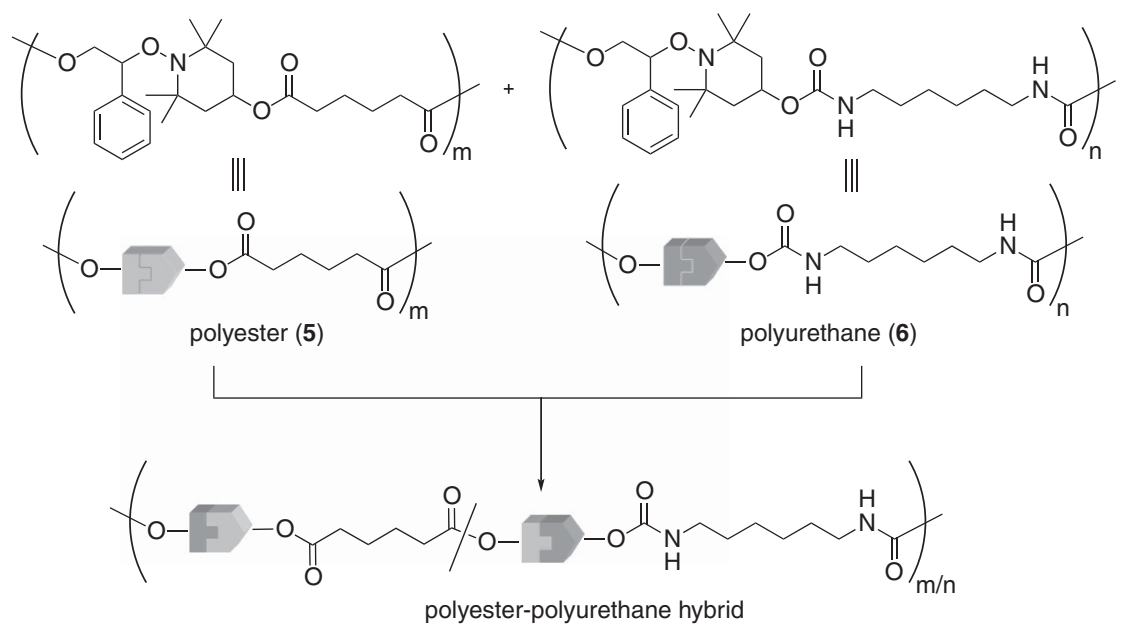

Scheme 9 Hybridization of polyester 5 and polyurethane 6 by polymer scrambling.

The polymerization behavior strongly depended on concentration. Furthermore, under high-dilution conditions, polymer 7 depolymerized to the monomer or oligomers mainly by the intramolecular radical exchange process (Scheme 8 ).

The above-mentioned exchange process is applicable to polymers with many functional groups because of the high tolerance of radical reactions for varying functionality. If the two different dynamic covalent polymers are mixed and the system is thermally reorganized, it can be expected that they will afford one hybridized polymer. These reorganizable polymers can facilitate a new polymer synthetic method-in particular, a method that is effective for the preparation of polymeric hybrid materials at the nanometer level. An innovative method for the hybridization of different dynamic covalent polymers by 'polymer scrambling' at the main-chain level was demonstrated by an alkoxyamine-containing dynamic covalent polyester and polyurethane (Scheme 9). ${ }^{69}$ By this method, the composition and blockiness of the polymers could be controlled, allowing the preparation of novel polymer nanohybrids by a combinatorial approach.

These findings strongly suggest that the main-chain-type alkoxyamine-containing dynamic covalent polymers are thermally reorganizable polymers. They can dissociate and associate reversibly in the main chain similarly to supramolecular polymers when triggered by external stimuli (in the present system, upon heating). This concept was further applied to other dynamic covalent chemistries, such as acylhydrazone exchange by acid treatment or heating, ${ }^{25,70-78}$ carbene dimerization by heating, ${ }^{79-81}$ olefin metathesis by metal catalyst, ${ }^{82}$ disulfide exchange by photoirradiation ${ }^{83}$ and so on. ${ }^{84}$

\section{REACTIONS OF SIDE-CHAIN-TYPE POLYMERS WITH ALKOXYAMINES}

The exchange reaction between polymer chains with alkoxyamine units is considered as a novel reversible polymer reaction system when it is applied to side-chain reactions. The composition of product polymers can be expected to depend on equilibrium control. This adaptability potentially offers the development of 'smart' materials that can respond to external stimuli through the use of reversible covalent bonds. ${ }^{85}$ To demonstrate the reorganization, side-chain-type alkoxyamine-containing polymers were synthesized and their reversible reactions were investigated.

Alkoxyamine-containing methacrylic ester (9) was prepared by the condensation reaction of alkoxyamine alcohol derivative $\mathbf{1 0}$ and methacryloyl chloride. To control the molecular weight via a facile 
procedure, metal-catalyzed living radical polymerization has been used. ${ }^{86}$ For the preparation of well-defined polymers with alkoxyamine units in the side chain, atom-transfer radical polymerization (ATRP) $)^{87-90}$ was employed. As mentioned above, the TEMPO-based alkoxyamine units do not dissociate below $60^{\circ} \mathrm{C}$. Therefore, the ATRP of methyl methacrylate (MMA) and methacrylic ester 9 was presumed to proceed without dissociation of the alkoxyamine units by conducting the polymerization below $60^{\circ} \mathrm{C}$, affording linear polymers (11) incorporating alkoxyamine units in the side chains with a high degree of molecular weight control. ${ }^{91}$ Accordingly, the ATRP of a 5:1 mixture of MMA and 9 was conducted in anisole at $50{ }^{\circ} \mathrm{C}$ using ethyl 2-bromoisobutyrate as the initiator and $\mathrm{Cu}(\mathrm{I}) \mathrm{Br} /$ sparteine as the catalyst complex. The observed $M_{\mathrm{n}} \mathrm{s}$ increased linearly with conversion and were in good agreement with those calculated, while polydispersities were relatively low $\left(M_{\mathrm{w}} / M_{\mathrm{n}}<1.23\right)$. The ${ }^{1} \mathrm{H}$ NMR spectrum of the resulting polymer revealed that the copolymer composition approximately corresponded to the feed ratio of the monomers (copolymer composition: $\mathrm{MMA} / \mathbf{9}=4.6 / 1)$.

On the other hand, the alkoxyamine-terminated polystyrene (12) was prepared through the conventional NMP procedure. ${ }^{56}$ Polymerization of styrene was conducted in bulk with the unimolecular initiator 13 at $125^{\circ} \mathrm{C}$ under argon to give a polystyrene with predictable molecular weight and low polydispersity. The ${ }^{1} \mathrm{H}$ NMR spectrum of $12 \mathrm{a} \quad\left(M_{\mathrm{n}}=1700, M_{\mathrm{w}} /\right.$ $\left.M_{\mathrm{n}}=1.15\right)$ showed that the alkoxyamine units were attached to the chain end of 12a. A mixture of 11a $\left(M_{\mathrm{n}}=11800, M_{\mathrm{w}} / M_{\mathrm{n}}=1.18\right.$, MMA/9 $=4.6 / 1)$ and $12 \mathrm{a}$ (5.0 equiv. per alkoxyamine units) was dissolved in anisole and heated at $100{ }^{\circ} \mathrm{C}$ under argon (Scheme 10). GPC measurement indicated an increase in the molecular weight of 11a caused by grafting via the radical crossover reaction of the alkoxyamine units. Confirmation of structure of the separated polymer $14 \mathrm{a}\left(M_{\mathrm{n}}=24000, M_{\mathrm{w}} / M_{\mathrm{n}}=1.16\right)$ was accomplished by ${ }^{1} \mathrm{H}$ NMR and IR measurements. By comparing the integral ratio of the signal for the unreacted alkoxyamine units and that for the methyl ester, the degree of grafting was estimated to be $58 \%$. The molecular weight calculated from the ${ }^{1} \mathrm{H}$ NMR spectrum was found to be 28200 . On the other hand, the $M_{\mathrm{n}}$ estimated by GPC measurement was 24000 , which was smaller than that estimated by ${ }^{1} \mathrm{H}$ NMR. This discrepancy in molecular weights is, however, fully consistent with the proposed structure, as the hydrodynamic volume of a graft polymer is less than that of a comparable linear polymer. ${ }^{92,93}$

To investigate the reversibility of the reaction system, a mixture of graft copolymer 14 and an excess amount (8.3 equiv. per alkoxyamine unit) of alkoxyamine derivative $\mathbf{1 3}$ was dissolved in anisole and heated at $100{ }^{\circ} \mathrm{C}$ under argon. As the reaction proceeded, the peak derived from 14 in the GPC profile shifted to the lower molecular weight region. Significantly, the GPC profile corresponding to the eliminated polystyrene $\left(M_{\mathrm{n}}=1700, M_{\mathrm{w}} / M_{\mathrm{n}}=1.15\right)$ appeared, and the integral ratio of the profile to the graft polymer increased with increasing reaction time. The de-grafting system reached equilibrium after $30 \mathrm{~h}$. Interestingly, the equilibrium $M_{\mathrm{n}}$ nearly corresponded to the initial $M_{\mathrm{n}}$ of 11a. These results indicated that the grafting system was produced by the exchange reaction of alkoxyamine groups and that the reaction was apparently reversible and under equilibrium control.

Side-chain-type reactions were further applied in a polymer brush to reversibly alternate its surface properties. ${ }^{94,95}$ Reactive poly(methacrylate)-based polymer brushes (15) with radically exchangeable alkoxyamine units in the side chains were prepared on flat silicon substrates, and their reactivities and surface properties were investigated (Scheme 11). The reactive polymer brushes (15) were prepared by surface-initiated ATRP, and the graft density of the brushes was estimated to be $\sim 0.36$ chains $\mathrm{nm}^{-2}$. Radical crossover reactions between the alkoxyamine units in the side chains of the polymer brushes and at the ends of the fluorinated polymer chains were carried out to afford polymer brushes with low surface free energies. In addition, de-grafting of the fluorinated polymer chains was also performed to confirm the reversibility of the radical crossover reactions. The surface properties of the polymer brushes after the grafting and de-grafting processes were characterized by X-ray photoelectron spectroscopy (XPS) and contact angle measurements. The composition calculated from XPS indicated that the reversible grafting of the fluorinated polymer chains had proceeded successfully. The surface wettability of the polymer brushes also changed after the grafting of the fluorinated polymers. Furthermore, after the de-grafting of the fluorinated polymer chains, the peaks
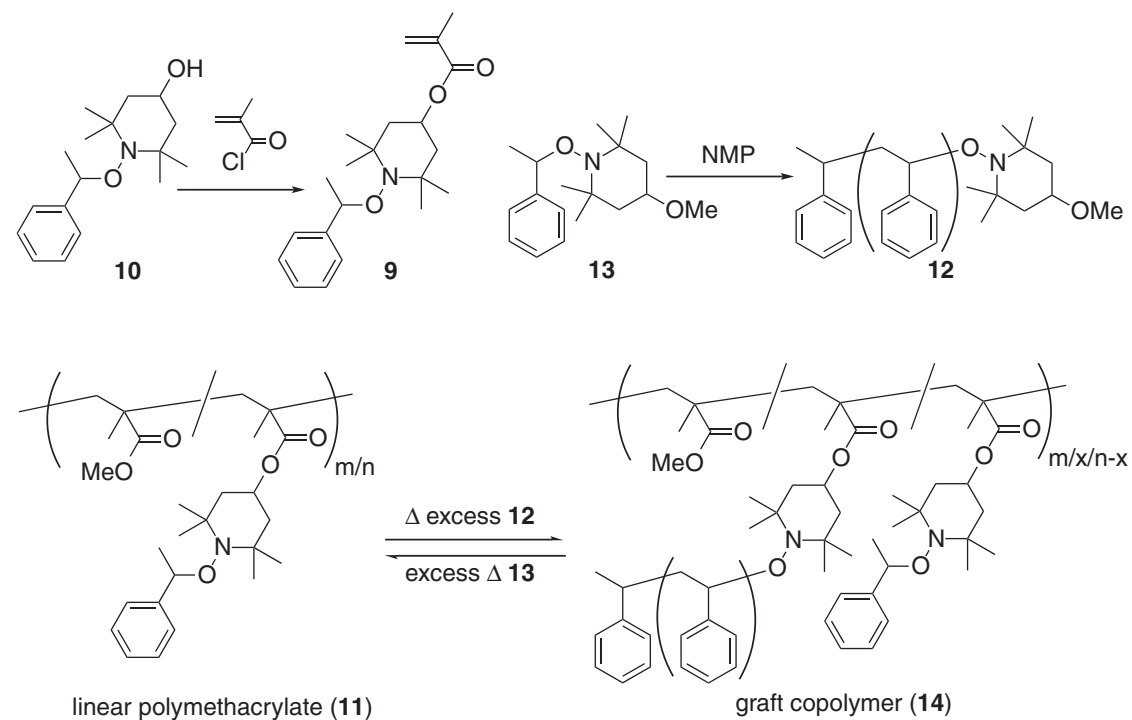

linear polymethacrylate (11)

graft copolymer (14)

Scheme 10 Preparation and dynamic grafting reaction of linear polymethacrylate with alkoxyamine units in the side chains and alkoxyamine-terminated polystyrene. 

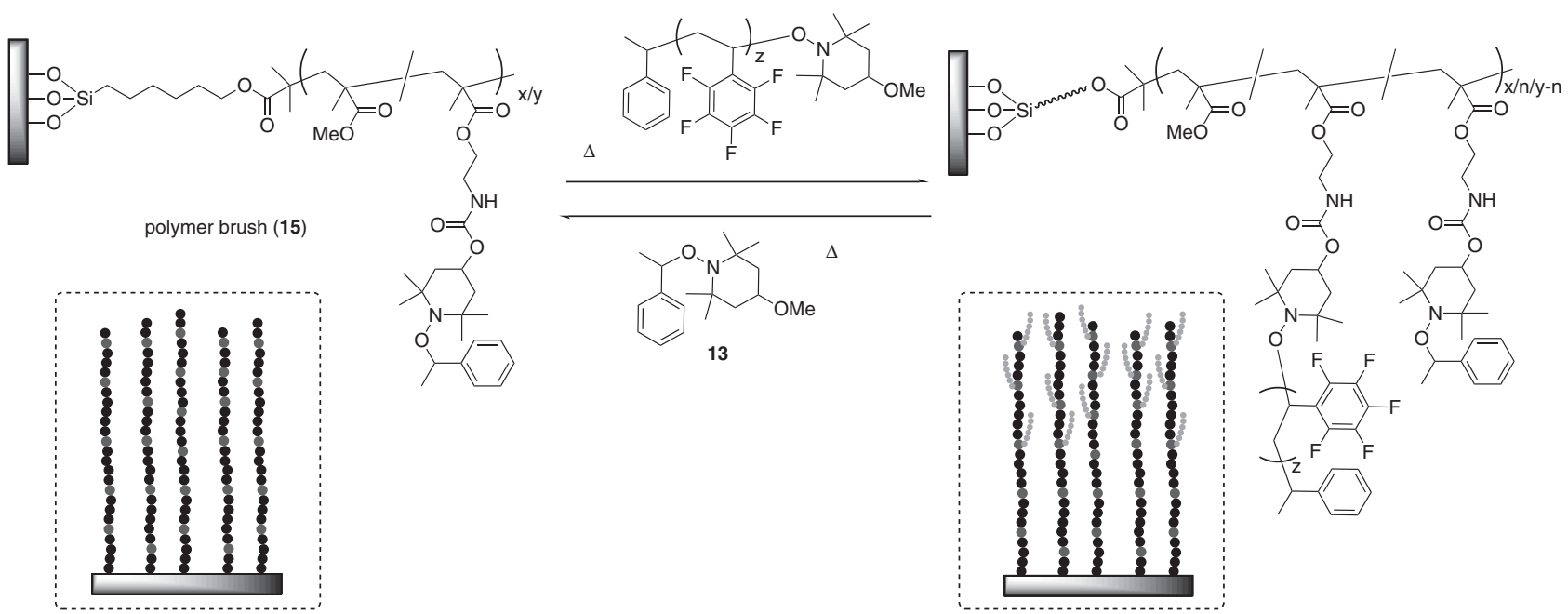

Scheme 11 Radical crossover reactions between alkoxyamine-containing polymer brushes and alkoxyamine-terminated fluorinated polymer. A full color version of this scheme is available at Polymer Journal online.
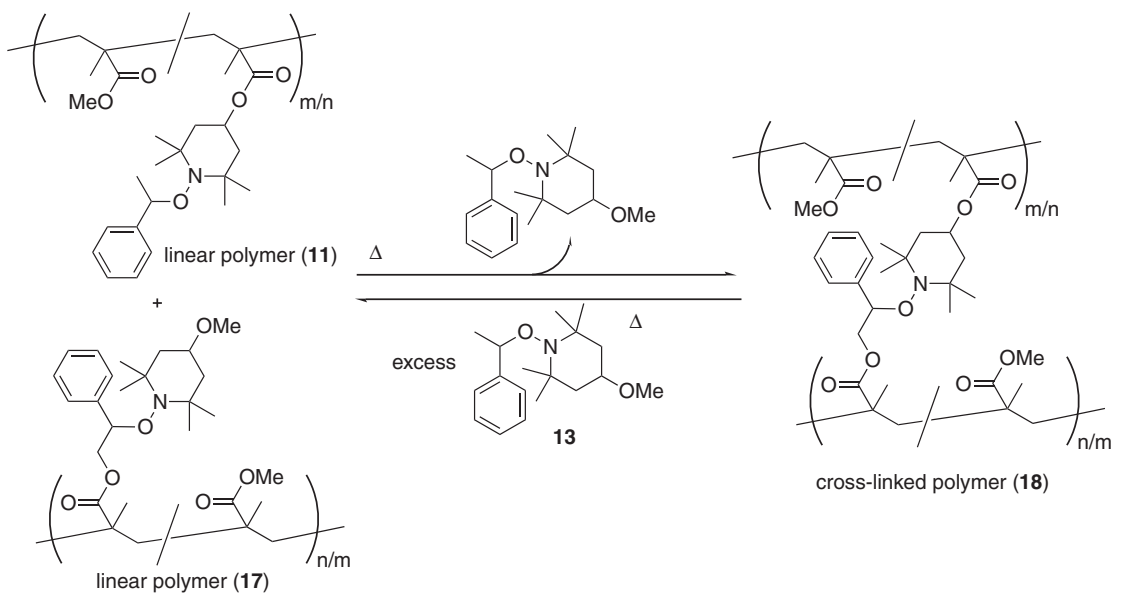

cross-linked polymer (18)

linear polymer (17)

Scheme 12 Reversible crosslinking reactions between linear polymethacrylate with complementarily reactive alkoxyamine units in their side chains.

attributed to fluorine atoms completely disappeared from the XPS spectrum and the wettability of the surface returned to that observed before grafting.

\section{REACTIONS OF POLYMERS CROSSLINKED BY ALKOXYAMINE UNITS}

Crosslinked polymers have been widely applied in various fields due to their attractive properties, such as adsorption of solvents ${ }^{96}$ and/or other substances, ${ }^{97}$ and their useful functionalities. ${ }^{98-101}$ Because the crosslinking points of typical crosslinked polymers such as poly(styrene-co-divinylbenzene) ${ }^{102}$ consist of strong and fixed covalent bonds, it is difficult to change their structures after preparation. Therefore, the crosslinking density and composition of a network polymer are determined in the preparation step. In contrast, dynamic covalent chemistry can impart reorganizability to crosslinked polymers. For example, a thermodynamic covalent crosslinking system based on the radical exchange reaction of alkoxyamine units was constructed, as represented in Scheme $12 .{ }^{103}$

The ATRP of MMA and methacrylic ester 9 or other methacrylic ester 16, which has been prepared by condensation of alkoxyamine alcohol derivative $\mathbf{2}$ and methacryloyl chloride, with the alkoxyamine moiety connected at different positions was performed with a
20/1 mixture of MMA and $\mathbf{9}$ or $\mathbf{1 6}$ in anisole at $50{ }^{\circ} \mathrm{C}$, using ethyl 2-bromoisobutyrate as the initiator and $\mathrm{Cu}(\mathrm{I}) \mathrm{Br} /$ sparteine as the catalyst complex. ${ }^{1} \mathrm{H}$ NMR measurement revealed that the composition of the resulting copolymers 11 and $\mathbf{1 7}$ approximately corresponded to the feed ratio of the monomers (copolymer composition: MMA/alkoxyamine-containing monomer $=19 / 1)$.

Before the polymer reaction between $11 b \quad\left(M_{\mathrm{n}}=16200\right.$, $\left.M_{\mathrm{w}} / M_{\mathrm{n}}=1.19, \quad \mathrm{MMA} / \mathbf{9}=19 / 1\right) \quad$ and $\mathbf{1 7 a} \quad\left(M_{\mathrm{n}}=15500, \quad M_{\mathrm{w}} /\right.$ $\left.M_{\mathrm{n}}=1.12, \quad \mathrm{MMA} / \mathbf{1 6}=19 / 1\right), 10 \mathrm{wt} \%$ anisole solutions of each polymer were heated independently at $100{ }^{\circ} \mathrm{C}$. In these cases, there was no change in the molecular weight or the molecular weight distribution. Crosslinking reactions were carried out by heating an anisole solution of the mixture of $\mathbf{1 1} \mathbf{b}$ and $\mathbf{1 7 a}$ at $100^{\circ} \mathrm{C}$ (Scheme 12). After heating, the solution was transformed into a gel at high concentrations. The crosslinking behavior remarkably depended upon the concentration. ${ }^{103}$

The reverse reaction, transformation from gel to solution, was examined through stoichiometric control. The crosslinked polymer 18 was swollen with anisole solution containing an excess amount of alkoxyamine 13 (20 equiv. per alkoxyamine unit) and heated at $100{ }^{\circ} \mathrm{C}$ for $48 \mathrm{~h}$. After heating, the sample was transformed from a gel state to a colorless solution. The molecular weight after the 


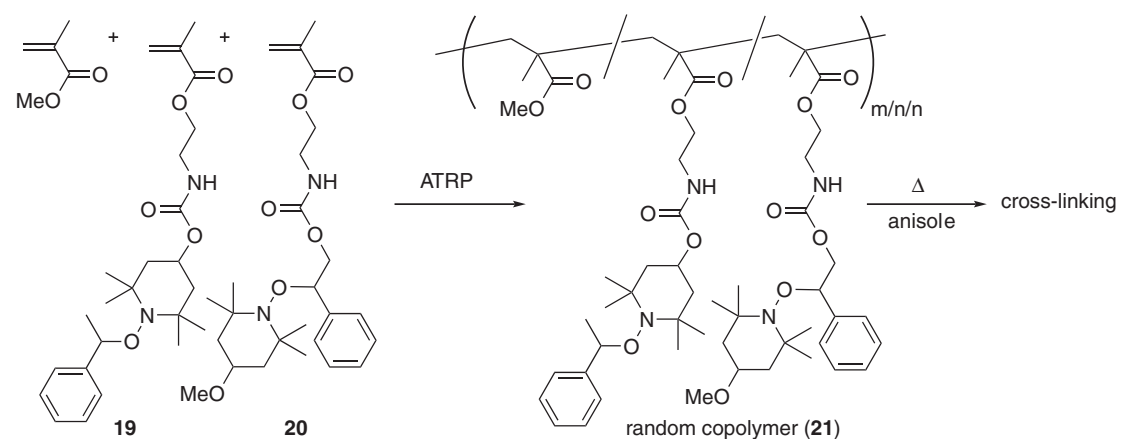

Scheme 13 Crosslinking reaction of linear polymethacrylate with complementarily reactive alkoxyamine units in the side chains.

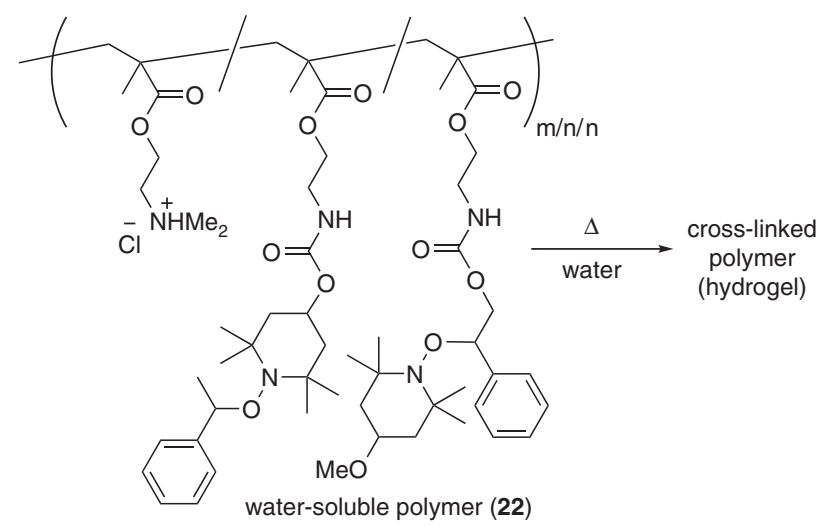

Scheme 14 Crosslinking reaction of water-soluble linear polymers with complementarily reactive alkoxyamine units in the side chains.

de-crosslinking reaction $\left(M_{\mathrm{n}}=17200, M_{\mathrm{w}} / M_{\mathrm{n}}=1.24\right)$ almost corresponded to that of a mixture of the starting polymers $\left(M_{\mathrm{n}}=15800\right.$, $\left.M_{\mathrm{w}} / M_{\mathrm{n}}=1.17\right)$

A smarter system was constructed by using random copolymers of methacrylic esters containing complimentarily reactive alkoxyamine units (Scheme 13). ${ }^{104}$ The random copolymers of MMA and two types of methacrylic esters (19 and 20) with alkoxyamines at different positions were synthesized by the ATRP method. A radical crossover reaction of random copolymer 21 was carried out by heating a degassed anisole solution of 21 at $100{ }^{\circ} \mathrm{C}$ at various concentrations. At high concentrations (above $5 \mathrm{wt} \%$ ), the solution was transformed into a macroscopic gel after heating for several hours, suggesting that the intermolecular crosslinking reaction occurred preferentially under such conditions. At low concentrations, however, no gelation was observed during the reaction, even after $24 \mathrm{~h}$. At $0.5 \mathrm{wt} \%$ concentration, the relative molecular weight did not increase, but rather decreased and peak broadening was observed. This result suggests that the intramolecular radical crossover reaction occurred preferentially and that the radius of gyration as well as the relative molecular weight of the polymer decreased after the reaction.

The reversible crosslinking of alkoxyamine-containing polymers in aqueous media was also accomplished (Scheme 14). ${ }^{105}$ Watersoluble polymers (22) with alkoxyamine units in the side chains were synthesized by the radical copolymerization of 2(dimethylamino)ethyl methacrylate and methacrylic esters with alkoxyamine units, and the subsequent protonation of the (dimethylamino)ethyl groups by hydrochloric acid. By heating the polymers in water at $100^{\circ} \mathrm{C}$ in a closed system, hydrogels were formed by radical exchange reactions. Because radical reactions are tolerant of water, the exchange reactions of the alkoxyamine units in the side
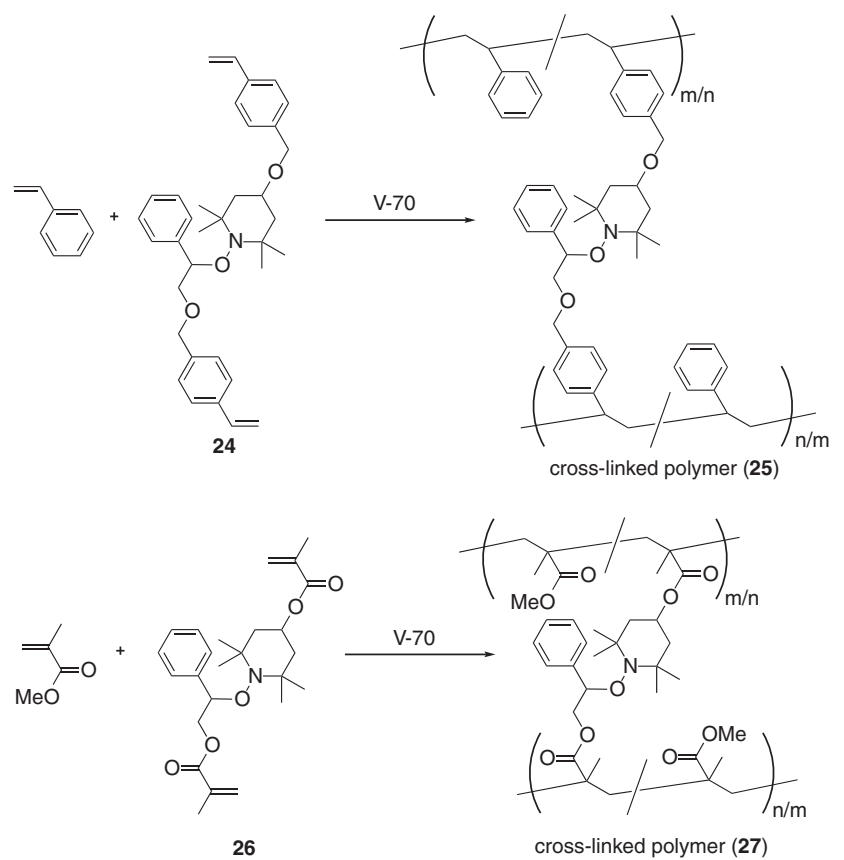

Scheme 15 Preparation of crosslinked polymers by radical copolymerization of vinyl monomers and bifunctional monomers with an alkoxyamine spacer.

chains caused the crosslinking reaction even in aqueous media. A decrosslinking reaction was also accomplished by a radical exchange reaction between the crosslinked polymer and an added hydrophilic alkoxyamine compound.

Crosslinked polymers can be synthesized not only by polymer reactions, but also by polymerization using bifunctional monomers as crosslinkers. Crosslinked polymers with alkoxyamine units at the crosslinking points were prepared by radical copolymerization of styrene and alkoxyamine-containing bifunctional monomer (24) (Scheme 15). ${ }^{106}$ The copolymerization was carried out in anisole at $40{ }^{\circ} \mathrm{C}$ with $\mathrm{V}-70$ as an initiator, which can generate radicals at relatively low temperature, to afford the corresponding polystyrenetype crosslinked polymers (25). Poly(methyl methacrylate) (PMMA)type crosslinked polymers (27) were also synthesized by radical copolymerization of MMA and alkoxyamine-containing bifunctional monomer (26) (Scheme 15). ${ }^{107}$ In both cases, de-crosslinking reactions and monomer insertion reactions were performed. The progress of the reactions was successfully characterized by dynamic viscoelasticity and small angle X-ray scattering measurements to show the reorganizability of the alkoxyaminecontaining crosslinked polymers. 

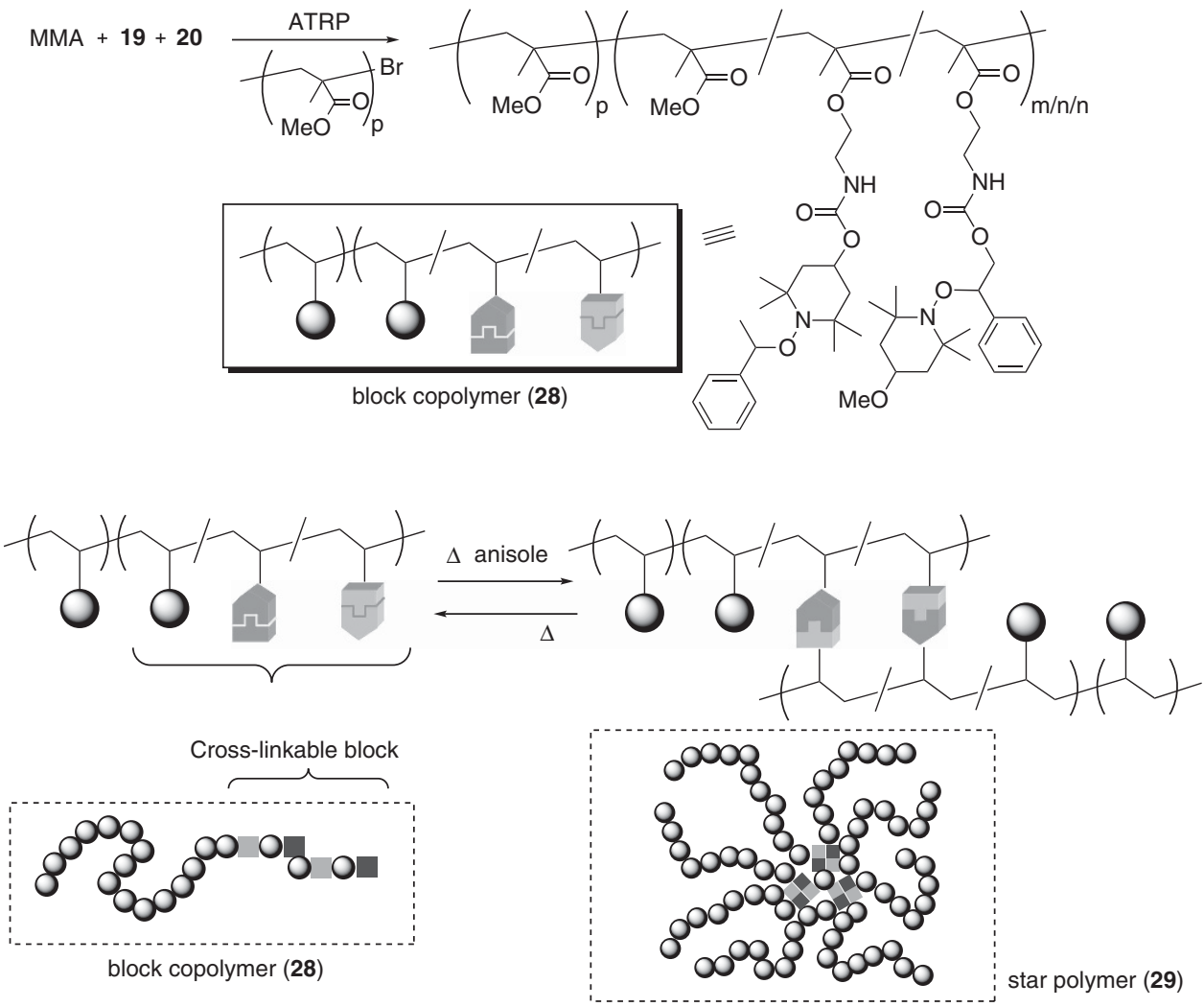

Scheme 16 Reversible formation of star polymers with crosslinked alkoxyamine core.
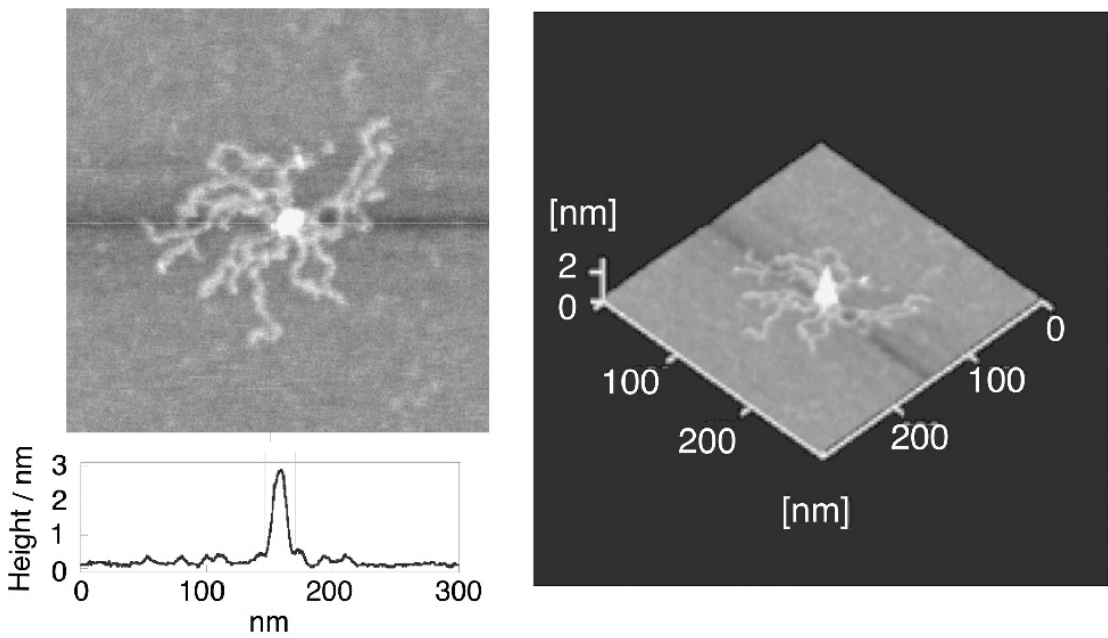

Figure 5 Scanning force microscopic image of a star polymer molecule on a mica substrate deposited from a solution of 29.

\section{SYNTHESIS AND REACTIONS OF STAR POLYMERS WITH CORES CROSSLINKED BY ALKOXYAMINE UNITS}

Star polymers were synthesized by radical crossover reactions of diblock copolymers with non-crosslinkable blocks and crosslinkable blocks. ${ }^{104,108-111}$ For example, linear diblock copolymers that consisted of PMMA blocks and random copolymer blocks of MMA and methacrylic esters (19 and 20) with an alkoxyamine moiety were prepared by ATRP (Scheme 16). ${ }^{104}$ By heating the diblock copolymers (28) in anisole, a crosslinking reaction occurred as a result of the radical crossover reaction of the alkoxyamine moieties to afford star polymers (29). The equilibrium structures of the star polymers were controlled by the initial concentrations of the diblock copolymers and their compositions and molecular weights. Additionally, by heating the star polymers with excess alkoxyamine, linear polymers were successfully regenerated. The molecular weights and sizes of the star polymers were evaluated by GPC-multiangle laser light scattering and small angle X-ray scattering measurements, respectively. The morphologies of the star polymers were directly observed by scanning force microscopy, which revealed that the star polymers consisted of both a core part and branching molecular chains (Figure 5). By controlling the stoichiometric ratio of the alkoxyamine, the structural conversion of the star polymers to diblock copolymers 

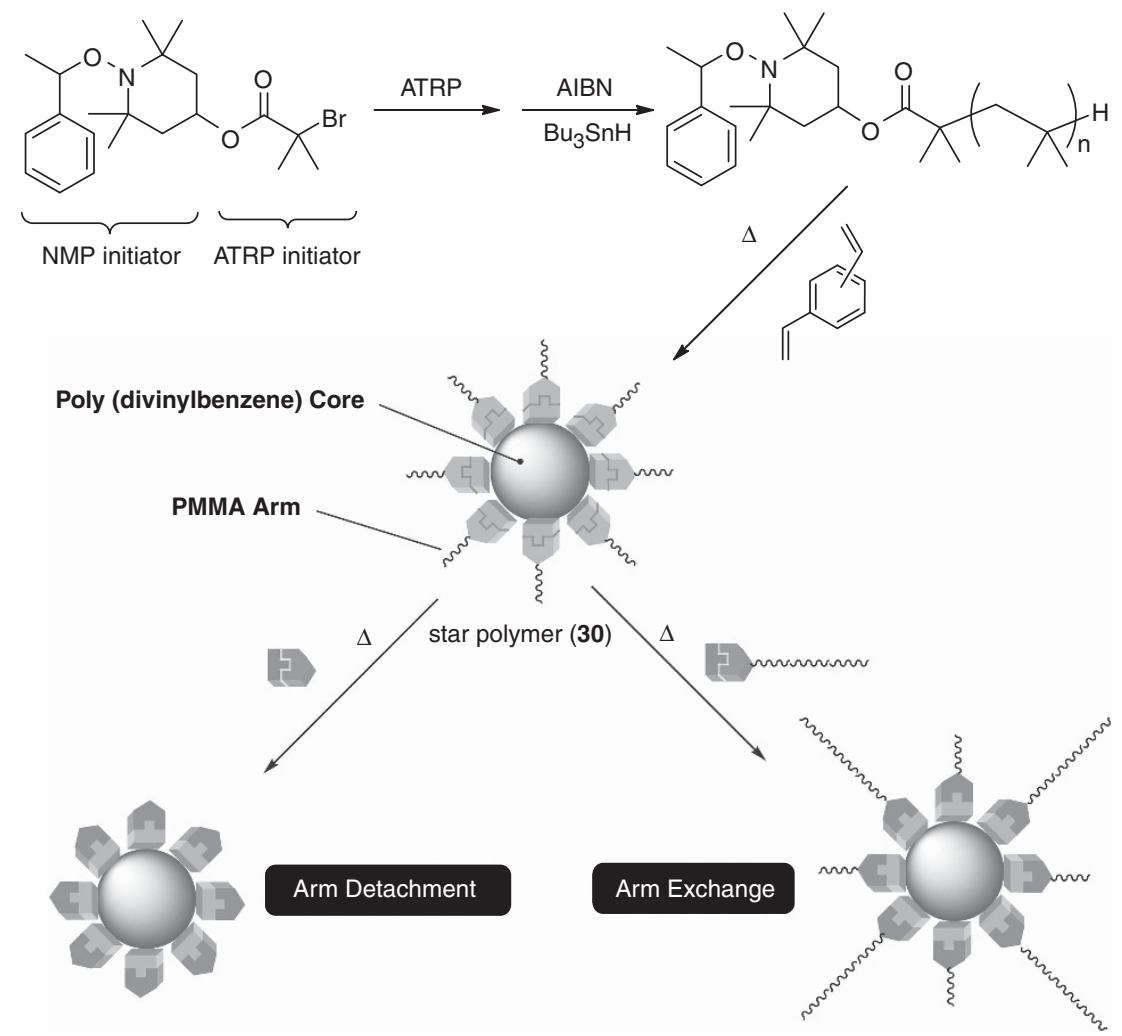

Scheme 17 Arm detachment and arm exchange of alkoxyamine-containing star polymers with a poly(divinylbenzene) core by radical crossover reactions.

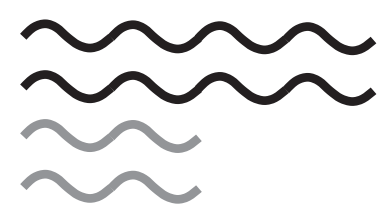

Linear

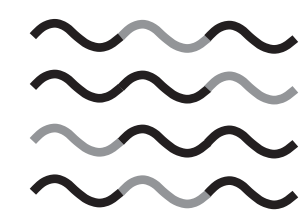

Multiblock

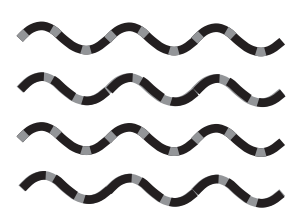

Random<smiles>CCCC(CC)CC(CC)CC(CCC)CC(CC)CCC</smiles>

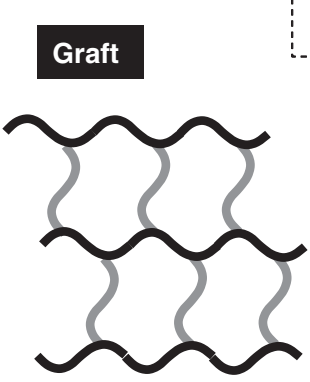

Cross-linked

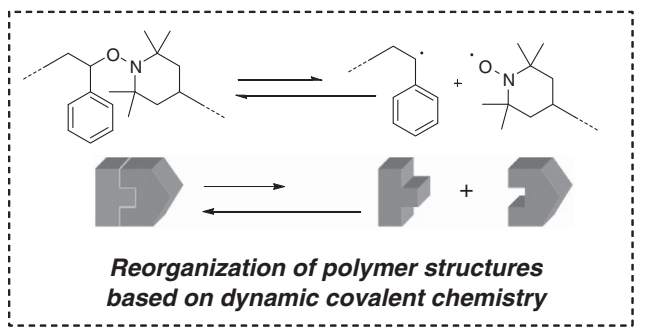

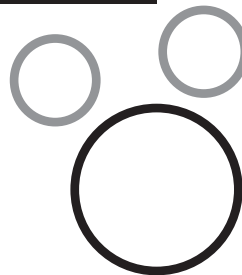

Cyclic

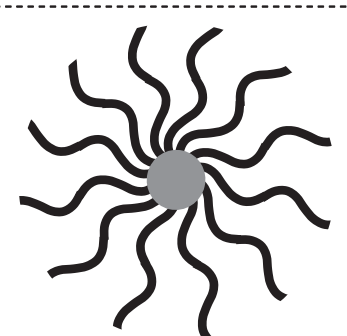

Star

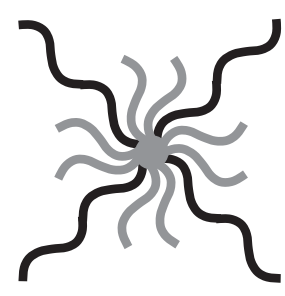

Mikto-arm Star

Figure 6 Conceptual representation for reorganization of polymer structures by dynamic covalent exchanges of alkoxyamine units. 
also proceeded, as the structures of the compound depend on the equilibrium state. Other dynamic covalent chemistries can also offer reversible transformations between diblock copolymers and star polymers. ${ }^{112-115}$

The formation of asymmetrical (miktoarm) star polymers by the crosslinking reaction of complementarily reactive diblock copolymers was also accomplished. ${ }^{109,110}$ Furthermore, the solvent-controlled formation of star polymers via a dynamic covalent exchange reaction of PSt- $b$-PMMA diblock copolymers with alkoxyamine units in the PMMA block was demonstrated. The reaction was carried out in decalin (a good solvent for PSt and a poor solvent for PMMA) and in anisole (a good solvent for both PSt and PMMA). ${ }^{11}$

The reorganization of star polymers, such as arm detachment or arm exchange reactions, was successfully demonstrated. ${ }^{116}$ Star polymers were designed and synthesized, and consisted of PMMA arms prepared by ATRP, and cores of poly(divinylbenzene) with alkoxyamine units at their branching points, prepared by NMP using functionalized PMMA as a macroinitiator (Scheme 17). Arm detachment reactions were carried out through radical crossover reactions by heating the star polymers (30) with excesses of small-molecule alkoxyamines, whereas arm exchange reactions were performed by heating the star polymers with higher molecular weight alkoxyamineterminated PMMA.

\section{SUMMARY}

In this review, various types of macromolecular designs and polymer reactions based on dynamic covalent exchanges of alkoxyamine units were described (Figure 6). The structures and constitutions of dynamic covalent polymers were reorganized under appropriate conditions even after polymerization. Main-chain-type, side-chaintype, crosslinked and star-shape alkoxyamine-containing dynamic covalent polymers were systematically introduced. The reorganization was confirmed by spectroscopic, chromatographic, microscopic and scattering methods. Furthermore, polymer reactions by dynamic covalent exchanges of alkoxyamine units were applied in an aqueous system. The dynamic crosslinking nature in aqueous media provides a foundation for a wide range of polymer reactions, and the process can be applied to environmentally benign dynamic materials. Polymer reactions by dynamic covalent exchange are being extended to other dynamic covalent chemistries. The research in this field is expected to expand and open the way to novel dynamic soft materials, such as self-healing polymers and mechano-responsive polymers.

\section{ACKNOWLEDGEMENTS}

I thank all colleagues and collaborators on this research project, particularly Professor A. Takahara, Dr Y. Higaki and Dr Y. Amamoto. I acknowledge the financial support of a Grant-in-Aid for Scientific Research from the Ministry of Education, Culture, Science, Sports and Technology (MEXT) of Japan; the Industrial Technology Research Grant Program of the New Energy and Industrial Technology Development Organization (NEDO) of Japan; and the Funding Program (Green Innovation GR077) for Next Generation World-Leading Researchers from the Cabinet Office, Government of Japan.

1 Kato, T. \& Frechet, J. M. J. Stabilization of a liquid-crystalline phase through noncovalent interaction with a polymer side-chain. Macromolecules 22, 3818-3819 (1989).

2 Lehn, J. M. Perspectives in supramolecular chemistry-from molecular recognition towards molecular information-processing and self-organization. Angew. Chem. Int. Ed. 29, 1304-1319 (1990).

3 Brunsveld, L., Folmer, B. J. B., Meijer, E. W. \& Sijbesma, R. P. Supramolecular polymers. Chem. Rev. 101, 4071-4097 (2001).
4 Yount, W. C., Juwarker, H. \& Craig, S. L. Orthogonal control of dissociation dynamics relative to thermodynamics in a main-chain reversible polymer. J. Am. Chem. Soc. 125, 15302-15303 (2003).

5 Miyauchi, M. \& Harada, A. Construction of supramolecular polymers with alternating alpha-, beta-cyclodextrin units using conformational change induced by competitive guests. J. Am. Chem. Soc. 126, 11418-11419 (2004).

6 Haino, T., Matsumoto, Y. \& Fukazawa, Y. Supramolecular nano networks formed by molecular-recognition-directed self-assembly of ditopic calix[5]arene and dumbbell [60]fullerene. J. Am. Chem. Soc. 127, 8936-8937 (2005).

7 Sijbesma, R. P., Beijer, F. H., Brunsveld, L., Folmer, B. J., Hirschberg, J. H., Lange, R. F., Lowe, J. K. \& Meijer, E. W. Reversible polymers formed from self-complementary monomers using quadruple hydrogen bonding. Science 278, 1601-1604 (1997).

8 Huc, I. \& Lehn, J. M. Virtual combinatorial libraries: dynamic generation of molecular and supramolecular diversity by self-assembly. Proc. Natl Acad. Sci. USA 94, 2106-2110 (1997).

9 Lehn, J. M. Dynamic combinatorial chemistry and virtual combinatorial libraries. Chem. Eur. J. 5, 2455-2463 (1999).

10 Otto, S., Furlan, R. L. E. \& Sanders, J. K. M. Dynamic combinatorial libraries of macrocyclic disulfides in water. J. Am. Chem. Soc. 122, 12063-12064 (2000).

11 Furlan, R. L. E., Otto, S. \& Sanders, J. K. M. Supramolecular templating in thermodynamically controlled synthesis. Proc. Natl Acad. Sci. USA 99, 4801-4804 (2002).

12 Otto, S., Furlan, R. L. E. \& Sanders, J. K. M. Selection and amplification of hosts from dynamic combinatorial libraries of macrocyclic disulfides. Science 297, 590-593 (2002).

13 Corbett, P. T., Leclaire, J., Vial, L., West, K. R., Wietor, J. L., Sanders, J. K. \& Otto, S. Dynamic combinatorial chemistry. Chem. Rev. 106, 3652-3711 (2006).

14 Ladame, S. Dynamic combinatorial chemistry: on the road to fulfilling the promise. Org. Biomol. Chem. 6, 219-226 (2008).

15 Bilig, T., Oku, T., Furusho, Y., Koyama, Y., Asai, S. \& Takata, T. Polyrotaxane networks formed via rotaxanation utilizing dynamic covalent chemistry of disulfide. Macromolecules 41, 8496-8503 (2008).

16 Furusho, Y., Oku, T., Hasegawa, T., Tsuboi, A., Kihara, N. \& Takata, T. Dynamic covalent approach to [2]- and [3]rotaxanes by utilizing a reversible thiol-disulfide interchange reaction. Chem. Eur. J. 9, 2895-2903 (2003).

17 Furusho, Y., Oku, T., Rajkumar, G. A. \& Takata, T. Dynamic covalent chemistry in rotaxane synthesis. Slipping approach to [2]rotaxane utilizing reversible cleavagerebondage of trityl thioether linkage. Chem. Lett. 33, 52-53 (2004).

18 Oku, T., Furusho, Y. \& Takata, T. First poly[3]rotaxane synthesized through the noncovalent step-growth polymerization of a homoditopic dumbbell compound and a macrocycle with a reversible thiol-disulfide interchange reaction. J. Polym. Sci. Pol. Chem. 41, 119-123 (2003).

19 Oku, T., Furusho, Y. \& Takata, T. A concept for recyclable cross-linked polymers: topologically networked polyrotaxane capable of undergoing reversible assembly and disassembly. Angew. Chem. Int. Ed. 43, 966-969 (2004).

20 Cantrill, S. J., Rowan, S. J. \& Stoddart, J. F. Rotaxane formation under thermodynamic control. Org. Lett. 1, 1363-1366 (1999).

21 Kidd, T. J., Leigh, D. A. \& Wilson, A. J. Organic 'magic rings'-the hydrogen bond-directed assembly of catenanes under thermodynamic control. J. Am. Chem. Soc. 121, 1599-1600 (1999)

22 Ramstrom, O. \& Lehn, J. M. Drug discovery by dynamic combinatorial libraries. Nat. Rev. Drug. Discov. 1, 26-36 (2002).

23 Levrand, B., Ruff, Y., Lehn, J. M. \& Herrmann, A. Controlled release of volatile aldehydes and ketones by reversible hydrazone formation-'classical' profragrances are getting dynamic. Chem. Commun. 2965-2967 (2006).

24 Rowan, S. J., Cantrill, S. J., Cousins, G. R. L., Sanders, J. K. M. \& Stoddart, J. F. Dynamic covalent chemistry. Angew. Chem. Int. Ed. 41, 898-952 (2002).

25 Skene, W. G. \& Lehn, J. M. P. Dynamers: polyacylhydrazone reversible covalent polymers, component exchange, and constitutional diversity. Proc. Natl Acad. Sci. USA 101, 8270-8275 (2004)

26 Wojtecki, R. J., Meador, M. A. \& Rowan, S. J. Using the dynamic bond to access macroscopically responsive structurally dynamic polymers. Nat. Mater. 10, 14-27 (2011)

27 Maeda, T., Otsuka, H. \& Takahara, A. Dynamic covalent polymers: reorganizable polymers with dynamic covalent bonds. Prog. Polym. Sci. 34, 581-604 (2009).

28 Kennedy, J. P. \& Castner, K. F. Thermally reversible polymer systems by cyclopentadienylation.2. Synthesis of cyclopentadiene-containing polymers. J. Polym. Sci. Pol. Chem. 17, 2055-2070 (1979).

29 Salamone, J. C., Chung, Y., Clough, S. B. \& Watterson, A. C. Thermally reversible, covalently crosslinked polyphosphazenes. J. Polym. Sci. Pol. Chem. 26, 2923-2939 (1988).

30 Chujo, Y., Sada, K. \& Saegusa, T. A novel nonionic hydrogel from 2-methyl-2 oxazoline.4. Reversible gelation of polyoxazoline by means of Diels-Alder reaction. Macromolecules 23, 2636-2641 (1990)

31 Chujo, Y., Sada, K. \& Saegusa, T. A Novel nonionic hydrogel from 2-methyl-2oxazoline.3. Polyoxazoline having a coumarin moiety as a pendant group-synthesis and photogelation. Macromolecules 23, 2693-2697 (1990).

32 Canary, S. A. \& Stevens, M. P. Thermally reversible cross-linking of polystyrene via the Furan-Maleimide Diels-Alder reaction. J. Polym. Sci. Pol. Chem. 30, 1755-1760 (1992).

33 Endo, T., Suzuki, T., Sanda, F. \& Takata, T. A novel network polymer linear polymer reversible arrow linear polymer reversible system. A new cross-linking system consisting of a reversible cross-linking-depolymerization of a polymer having a spiro orthoester moiety in the side chain. Macromolecules 29, 4819-4819 (1996). 
34 Endo, T., Suzuki, T., Sanda, F. \& Takata, T. A novel approach for the chemical recycling of polymeric materials: the network polymer reversible arrow bifunctional monomer reversible system. Macromolecules 29, 3315-3316 (1996).

35 Ilhan, F. \& Rotello, V. M. Thermoreversible polymerization. Formation of fullerenediene oligomers and copolymers. J. Org. Chem. 64, 1455-1458 (1999).

36 Yoshida, K., Sanda, F. \& Endo, T. Synthesis and cationic ring-opening polymerization of mono- and bifunctional spiro orthoesters containing ester groups and depolymerization of the obtained polymers: an approach to chemical recycling for polyesters as a model system. J. Polym. Sci. Pol. Chem. 37, 2551-2558 (1999).

37 Scott, T. F., Schneider, A. D., Cook, W. D. \& Bowman, C. N. Photoinduced plasticity in cross-linked polymers. Science 308, 1615-1617 (2005).

38 Ishida, K. \& Yoshie, N. Two-way conversion between hard and soft properties of semicrystalline cross-linked polymer. Macromolecules 41, 4753-4757 (2008).

39 Kloxin, C. J., Scott, T. F., Adzima, B. J. \& Bowman, C. N. Covalent Adaptable Networks (CANS): a unique paradigm in cross-linked polymers. Macromolecules $\mathbf{4 3}$ 2643-2653 (2010).

40 Ishida, K., Nishiyama, Y., Michimura, Y., Oya, N. \& Yoshie, N. Hard-soft conversion in network polymers: effect of molecular weight of crystallizable prepolymer. Macromolecules 43, 1011-1015 (2010).

41 Amamoto, Y. Kamada, J., Otsuka, H., Takahara, A. \& Matyjaszewski, K. Polymers through reshuffling of trithiocarbonate units. Angew. Chem. Int. Ed. 50, 1660-1663 (2011).

42 Montarnal, D., Capelot, M., Tournilhac, F. \& Leibler, L. Silica-like malleable materials from permanent organic networks. Science 334, 965-968 (2011).

43 Lu, Y. X., Tournilhac, F., Leibler, L. \& Guan, Z. B. Making insoluble polymer networks malleable via olefin metathesis. J. Am. Chem. Soc. 134, 8424-8427 (2012).

44 Capelot, M., Montarnal, D., Tournilhac, F. \& Leibler, L. Metal-catalyzed transesterification for healing and assembling of thermosets. J. Am. Chem. Soc. 134, 7664-7667 (2012).

45 Amamoto, Y., Otsuka, H., Takahara, A. \& Matyjaszewski, K. Changes in network structure of chemical gels controlled by solvent quality through photoinduced radical reshuffling reactions of trithiocarbonate units. Acs. Macro. Lett. 1, 478-481 (2012).

46 Georges, M. K., Veregin, R. P. N., Kazmaier, P. M. \& Hamer, G. K. Narrow molecularweight resins by a free-radical polymerization process. Macromolecules 26 2987-2988 (1993).

47 Studer, A. \& Schulte, T. Nitroxide-mediated radical processes. Chem. Rec. 5, 27-35 (2005)

48 Tebben, L. \& Studer, A. Nitroxides: applications in synthesis and in polymer chemistry. Angew. Chem. Int. Ed. 50, 5034-5068 (2011).

49 Matsuno, R., Yamamoto, K., Otsuka, H. \& Takahara, A. Polystyrene-grafted magnetite nanoparticles prepared through surface-initiated nitroxyl-mediated radical polymerization. Chem. Mater. 15, 3-5 (2003).

50 Matsuno, R., Yamamoto, K., Otsuka, H. \& Takahara, A. Polystyrene- and poly(3 vinylpyridine)-grafted magnetite nanoparticles prepared through surface-initiated nitroxide-mediated radical polymerization. Macromolecules 37, 2203-2209 (2004).

51 Miyamoto, K., Hosaka, N. Otsuka, H. \& Takahara, A. Stabilization of polystyrene thin films against dewetting by silsesquioxane-terminated polystyrene additives. Chem. Lett. 35, 1098-1099 (2006).

52 Miyamoto, K., Hosaka, N., Kobayashi, M., Otsuka, H., Yamada, N., Torikai, N. \& Takahara, A. Dewetting inhibition and interfacial structures of silsesquioxaneterminated polystyrene thin films. Polym. J. 39, 1247-1252 (2007).

53 Yukutake, H., Kobayashi, M., Otsuka, H. \& Takahara, A. Influence of magadiite dispersion states on the flammability of polystyrene and polyphenylene etherpolystyrene alloy nanocomposites. Polym. J. 42, 223-231 (2010).

54 Yukutake, H., Kobayashi, M., Otsuka, H. \& Takahara, A. Thermal degradation behavio of polystyrene/magadiite nanocomposites prepared by surface-initiated nitroxidemediated radical polymerization. Polym. J.41, 555-561 (2009).

55 Ohno, K., Tsujii, Y. \& Fukuda, T. Mechanism and kinetics of nitroxide-controlled free radical polymerization. Thermal decomposition of 2,2,6,6-tetramethyl-1-polystyroxypiperidines. Macromolecules 30, 2503-2506 (1997).

56 Hawker, C. J. Molecular-weight control by a living free-radical polymerization process. J. Am. Chem. Soc. 116, 11185-11186 (1994).

57 Hawker, C. J., Bosman, A. W. \& Harth, E. New polymer synthesis by nitroxide mediated living radical polymerizations. Chem. Rev. 101, 3661-3688 (2001).

58 Hawker, C. J., Barclay, G. G. \& Dao, J. L. Radical crossover in nitroxide mediated "living" free radical polymerizations. J. Am. Chem. Soc. 118, 11467-11471 (1996)

59 Turro, N. J., Lem, G. \& Zavarine, I. S. A living free radical exchange reaction for the preparation of photoactive end-labeled monodisperse polymers. Macromolecules 33 9782-9785 (2000).

60 Otsuka, H., Aotani, K., Higaki, Y. \& Takahara, A. A dynamic (reversible) covalent polymer: radical crossover behaviour of TEMPO-containing poly(alkoxyamine ester)s. Chem. Commun. 2838-2839 (2002).

61 Studer, A. Tin-free radical cyclization reactions using the persistent radica effect. Angew. Chem. Int. Ed. 39, 1108-1111 (2000).

62 Studer, A. The persistent radical effect in organic synthesis. Chem. Eur. J. 7, 1159-1164 (2001).

63 Studer, A. Tin-free radical chemistry using the persistent radical effect: alkoxyamine isomerization, addition reactions and polymerizations. Chem. Soc. Rev. 33, 267-273 (2004)

64 Tang, W., Fukuda, T. \& Matyjaszewski, K. Reevaluation of persistent radical effect in NMP. Macromolecules 39, 4332-4337 (2006).
65 Otsuka, H., Aotani, K., Higaki, Y., Amamoto, Y. \& Takahara, A. Thermal reorganization and molecular weight control of dynamic covalent polymers containing alkoxyamines in their main chains. Macromolecules 40, 1429-1434 (2007).

66 Higaki, Y., Otsuka, H., Endo, T. \& Takahara, A. Polyurethane macroinitiator for controlled monomer insertion of styrene. Macromolecules 36, 1494-1499 (2003).

67 Yamaguchi, G., Higaki, Y., Otsuka, H. \& Takahara, A. Reversible radical ring-crossover polymerization of an alkoxyamine-containing dynamic covalent macrocycle. Macromolecules 38, 6316-6320 (2005).

68 Narumi, A., Zeidler, S., Barqawi, H., Enders, C. \& Binder, W. H. Cyclic alkoxyamineinitiator tethered by azide/alkyne-'click'-chemistry enabling ring-expansion viny polymerization providing macrocyclic polymers. J. Polym. Sci. Pol. Chem. 48, 3402-3416 (2010).

69 Otsuka, H., Aotani, K., Higaki, Y. \& Takahara, A. Polymer scrambling: macromolecular radical crossover reaction between the main chains of alkoxyamine-based dynamic covalent polymers. J. Am. Chem. Soc. 125, 4064-4065 (2003).

70 Ono, T., Nobori, T. \& Lehn, J. M. Dynamic polymer blends-component recombination between neat dynamic covalent polymers at room temperature. Chem. Commun. 1522-1524 (2005)

71 Ono, T., Fujii, S., Nobori, T. \& Lehn, J. M. Soft-to-hard transformation of the mechanical properties of dynamic covalent polymers through component incorporation. Chem. Commun. 46-48 (2007).

72 Ono, T., Fujii, S., Nobori, T. \& Lehn, J. M. Optodynamers: expression of color and fluorescence at the interface between two films of different dynamic polymers. Chem. Commun. 4360-4362 (2007)

73 Chow, C. F., Fujii, S. \& Lehn, J. M. Crystallization-driven constitutional changes of dynamic polymers in response to neat/solution conditions. Chem. Commun. 4363-4365 (2007).

74 Chow, C. F., Fujii, S. \& Lehn, J. M. Metallodynamers: neutral dynamic metallosupramolecular polymers displaying transformation of mechanical and optical properties on constitutional exchange. Angew. Chem. Int. Ed. 46, 5007-5010 (2007).

75 Chow, C. F., Fujii, S. \& Lehn, J. M. Metallodynamers: neutral double-dynamic metallosupramolecular polymers. Chem. Asian J. 3, 1324-1335 (2008).

76 Nasr, G., Barboiu, M., Ono, T., Fujii, S. \& Lehn, J. M. Dynamic polymer membranes displaying tunable transport properties on constitutional exchange. J. Membrane Sci. 321, 8-14 (2008)

77 Fujii, S. \& Lehn, J. M. Structural and Functional evolution of a library of constitutional dynamic polymers driven by alkali metal ion recognition. Angew. Chem. Int. Ed. 48, 7635-7638 (2009).

78 Folmer-Andersen, J. F. \& Lehn, J. M. Thermoresponsive dynamers: thermally induced, reversible chain elongation of amphiphilic poly(acylhydrazones). J. Am. Chem. Soc. 133, 10966-10973 (2011).

79 Kamplain, J. W. \& Bielawski, C. W. Dynamic covalent polymers based upon carbene dimerization. Chem. Commun. 1727-1729 (2006).

80 Norris, B. C. \& Bielawski, C. W. Structurally dynamic materials based on bis (N-heterocyclic carbene)s and bis(isothiocyanate)s: toward reversible, conjugated polymers. Macromolecules 43, 3591-3593 (2010).

81 Neilson, B. M., Tennyson, A. G. \& Bielawski, C. W. Advances in bis(N-heterocyclic carbene) chemistry: new classes of structurally dynamic materials. J. Phys. Org. Chem. 25, 531-543 (2012).

82 Otsuka, H., Muta, T., Sakada, M., Maeda, T. \& Takahara, A. Scrambling reaction between polymers prepared by step-growth and chain-growth polymerizations: macromolecular cross-metathesis between 1,4-polybutadiene and olefin-containing polyester. Chem. Commun. 1073-1075 (2009).

83 Otsuka, H. Nagano, S., Kobashi, Y., Maeda, T. \& Takahara, A A dynamic covalent polymer driven by disulfide metathesis under photoirradiation. Chem. Commun. 46, 1150-1152 (2010)

84 Tennyson, A. G., Norris, B. \& Bielawski, C. W. Structurally dynamic conjugated polymers. Macromolecules 43, 6923-6935 (2010).

85 Lehn, J. M. From supramolecular chemistry towards constitutional dynamic chemistry and adaptive chemistry. Chem. Soc. Rev. 36, 151-160 (2007).

86 Kamigaito, M., Ando, T. \& Sawamoto, M. Metal-catalyzed living radical polymerization. Chem. Rev. 101, 3689-3745 (2001).

87 Wang, J. S. \& Matyjaszewski, K. Controlled living radical polymerization-halogen atom-transfer radical polymerization promoted by a $\mathrm{Cu}(\mathrm{I}) \mathrm{Cu}(\mathrm{li})$ redox process. Macromolecules 28, 7901-7910 (1995)

88 Wang, J. S. \& Matyjaszewski, K. Controlled living radical polymerization-atom-transfer radical polymerization in the presence of transition-metal complexes. J. Am. Chem. Soc. 117, 5614-5615 (1995).

89 Patten, T. E., Xia, J. H., Abernathy, T. \& Matyjaszewski, K. Polymers with very low polydispersities from atom transfer radical polymerization. Science $\mathbf{2 7 2 , 8 6 6 - 8 6 8}$ (1996).

90 Matyjaszewski, K. \& Xia, J. H. Atom transfer radical polymerization. Chem. Rev. 101, 2921-2990 (2001)

91 Higaki, Y., Otsuka, H. \& Takahara, A. Dynamic formation of graft polymers via radical crossover reaction of alkoxyamines. Macromolecules 37, 1696-1701 (2004).

92 Hawker, C. J. Architectural control in living free-radical polymerizations-preparation of star and graft polymers. Angew. Chem. Int. Ed. 34, 1456-1459 (1995).

93 Grubbs, R. B., Hawker, C. J., Dao, J. \& Frechet, J. M. J. A tandem approach to graft and dendritic graft copolymers based on 'living' free radical polymerizations. Angew. Chem. Int. Ed. 36, 270-272 (1997).

94 Sato, T., Amamoto, Y., Yamaguchi, H., Otsuka, H. \& Takahara, A. "Substitutable" polymer brushes: reactive poly(methacrylate) brushes with exchangeable alkoxyamine units in the side chain. Chem. Lett. 39, 1209-1211 (2010) 
95 Sato, T., Amamoto, Y., Yamaguchi, H., Ohishi, T., Takahara, A. \& Otsuka, H. Dynamic covalent polymer brushes: reversible surface modification of reactive polymer brushes with alkoxyamine-based dynamic covalent bonds. Polym. Chem. 3, 3077-3083 (2012).

96 Tanaka, T., Sun, S. T., Hirokawa, Y., Katayama, S., Kucera, J., Hirose, Y. \& Amiya, T. Mechanical instability of gels at the phase-transition. Nature 325, 796-798 (1987).

97 Esser-Kahn, A. P., lavarone, A. T. \& Francis, M. B. Metallothionein-cross-linked hydrogels for the selective removal of heavy metals from water. J. Am. Chem. Soc. 130, 15820 (2008).

98 Yoshida, R., Takahashi, T., Yamaguchi, T. \& Ichijo, H. Self-oscillating gel. J. Am Chem. Soc. 118, 5134-5135 (1996).

99 Okumura, Y. \& Ito, K. The polyrotaxane gel: a topological gel by figure-of-eight crosslinks. Adv. Mater. 13, 485-487 (2001).

100 Haraguchi, K. \& Takehisa, T. Nanocomposite hydrogels: a unique organic-inorganic network structure with extraordinary mechanical, optical, and swelling/de-swelling properties. Adv. Mater. 14, 1120-1124 (2002).

101 Gong, J. P., Katsuyama, Y., Kurokawa, T. \& Osada, Y. Double-network hydrogels with extremely high mechanical strength. Adv. Mater. 15, 1155-1158 (2003).

102 Worsfold, D. J. Anionic copolymerization of styrene with para-divinylbenzene. Macromolecules 3, 514-517 (1970).

103 Higaki, Y., Otsuka, H. \& Takahara, A. A thermodynamic polymer cross-linking system based on radically exchangeable covalent bonds. Macromolecules 39, 2121-2125 (2006).

104 Amamoto, Y., Higaki, Y., Matsuda, Y., Otsuka, H. \& Takahara, A. Programmed thermodynamic formation and structure analysis of star-like nanogels with core cross-linked by thermally exchangeable dynamic covalent bonds. J. Am. Chem. Soc. 129, 13298-13304 (2007).

105 Su, J., Amamoto, Y., Nishihara, M., Takahara, A. \& Otsuka, H. Reversible crosslinking of hydrophilic dynamic covalent polymers with radically exchangeable alkoxyamines in aqueous media. Polym. Chem. 2, 2021-2026 (2011).

106 Amamoto, Y. Kikuchi, M. Masunaga, H. Sasaki, S., Otsuka, H. \& Takahara, A. Reorganizable chemical polymer gels based on dynamic covalent exchange and controlled monomer insertion. Macromolecules 42, 8733-8738 (2009).
107 Amamoto, Y., Kikuchi, M., Masunaga, H., Ogawa, H., Sasaki, S., Otsuka, H. \& Takahara, A. Mesh-size control and functionalization of reorganizable chemical gels by monomer insertion into their cross-linking points. Polym. Chem. 2, 957-962 (2011)

108 Amamoto, Y., Higaki, Y., Matsuda, Y., Otsuka, H. \& Takahara, A. Programmed formation of nanogels via a radical crossover reaction of complementarily reactive diblock copolymers. Chem. Lett. 36, 774-775 (2007).

109 Amamoto, Y., Maeda, T., Kikuchi, M., Otsuka, H. \& Takahara, A. Rational approach to star-like nanogels with different arm lengths: formation by dynamic covalent exchange and their imaging. Chem. Commun. 689-691 (2009)

110 Amamoto, Y., Kikuchi, M., Otsuka, H. \& Takahara, A. Intelligent build-up of complementarily reactive diblock copolymers via dynamic covalent exchange toward symmetrical and miktoarm star-like nanogels. Macromolecules 43, 1785-1791 (2010)

111 Amamoto, Y., Kikuchi, M., Otsuka, H. \& Takahara, A. Solvent-controlled formation of star-like nanogels via dynamic covalent exchange of PSt-b-PMMA diblock copolymers with alkoxyamine units in the side chain. Macromolecules 43, 5470-5473 (2010)

112 Jackson, A. W. \& Fulton, D. A. The formation of core cross-linked star polymers containing cores cross-linked by dynamic covalent imine bonds. Chem. Commun. 46, 6051-6053 (2010)

113 Jackson, A. W. \& Fulton, D. A. pH triggered self-assembly of core cross-linked star polymers possessing thermoresponsive cores. Chem. Commun. 47, 6807-6809 (2011).

114 Jackson, A. W., Stakes, C. \& Fulton, D. A. The formation of core cross-linked star polymer and nanogel assemblies facilitated by the formation of dynamic covalent imine bonds. Polym. Chem. 2, 2500-2511 (2011).

115 Bapat, A. P., Roy, D., Ray, J. G., Savin, D. A. \& Sumerlin, B. S. Dynamic-covalent macromolecular stars with boronic ester linkages. J. Am. Chem. Soc. 133, 19832-19838 (2011).

116 Amamoto, Y., Kikuchi, M., Otsuka, H. \& Takahara, A. Arm-replaceable star-like nanogels: arm detachment and arm exchange reactions by dynamic covalent exchanges of alkoxyamine units. Polym. J. 42, 860-867 (2010).

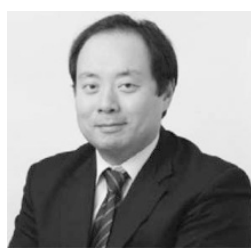

Hideyuki Otsuka received his Ph.D. from Kyushu University in 1996 under the supervision of Professor Seiji Shinkai. He then moved to The University of Birmingham, UK, as a visiting fellow. In 1997, he was appointed as an Assistant Professor in the laboratory of Professor Takeshi Endo, Tokyo Institute of Technology. There, he started his research on polymer chemistry. In 2000, he was appointed as an Associate Professor (Professor Atsushi Takahara Laboratory) at the Kyushu University. His research interests focus on reorganizable dynamic covalent polymers. He received a Young Scientist Award from MEXT (Ministry of Education, Culture, Sports, Science and Technology), Japan, in 2005, and a SPSJ (Society of Polymer Science, Japan) Wiley Award in 2012. 